\title{
MULTICHANNEL INTRALUMINAL IMPEDANCE AND pH
}

Domingues G. Multichannel intraluminal impedance and pH. Arq Gastroenterol. 2016;53(3):129

I read with interest the article by Bortoli $\mathrm{N}$ et al. ${ }^{(2)}$ investigating the efficacy of combined multichannel intraluminal impedance (MII) and $\mathrm{pH}$ to detect association between typical and atypical gastroesophageal reflux disease (GERD) symptoms and reflux events as compared to esophageal $\mathrm{pH}$ monitoring alone. In this study, the authors found that MII technology and $\mathrm{pH}$ had a higher diagnostic accuracy in detecting reflux events as well as association with GERD symptoms.

GERD develops when the reflux of gastric contents causes troublesome symptoms and/or complications ${ }^{(7)}$. It is a highly prevalent disease in Brazil, affecting up to $12 \%$ of the general population ${ }^{(9)}$. As seen in the Bortoli's study, GERD symptoms, either typical or atypical, can be associated with acid reflux events and non-acid (weakly acid) reflux events. MII is a relatively new technology that detect anterograde or retrograde movement of solid, fluid and air in the esophagus regardless of its $\mathrm{pH}$.

MII combined with a conventional $\mathrm{pH}$ sensor provides a full characterization of reflux events related to its chemical properties (acid or non-acid reflux) and physical properties (liquid, gas, mixed). This technology shed new light in investigation of patients with persistent symptoms despite adequate esophageal acid exposure control by proton pump inhibitors (PPI) ${ }^{(5)}$. In this regard, MII-pH monitoring has improved the diagnostic yield of GERD patients as it provides better identification of patients with functional heartburn. NERD patients vary greatly from a pathophysiological point of view and should be accurately studied by means of MII-pH to undertake the best therapeutic approach. Furthermore, it is an utmost tool to identify non-acid reflux events associated with typical and atypical symptoms as is the case in chronic cough investigation ${ }^{(8)}$. It seems that nonacid reflux does not appear to be directly related to the development of esophageal mucosa lesions; however, it is definitely involved in the genesis of symptoms in both NERD and erosive esophagitis patients ${ }^{(1)}$.

The introduction of new parameters in MII-pH studies, such as the post-reflux swallow-induced peristaltic wave (PSPW) index, which indicates the efficacy of esophageal clearance ${ }^{(3)}$, and baseline impedance values, which indicate the presence of a lack of integrity in the esophageal mucosa ${ }^{(4)}$ unmasked GERD in patients whose association between reflux events and symptoms was not evident. PSPW has been shown to be lower in patients with abnormal acid exposure time (AET), compared to healthy volunteers or functional heartburn patients ${ }^{(3)}$. Patients with abnormal AET have lower values of baseline impedance levels in the distal esophagus compared to healthy controls and patients with functional heartburn ${ }^{(6)}$.

MII-pH studies can be performed "on" and "off" PPI therapy. Basically, when the diagnosis of GERD has not been established, MII-pH studies should be better performed off-PPI therapy. On the other hand, MII$\mathrm{pH}$ studies on-PPI therapy are prone to those patients whose GERD diagnosis has already been made and persistence of symptoms exists or Barrett's esophagus surveillance is necessary.

In conclusion, MII-pH is a valuable method to diagnose GERD. MII-pH is more accurate in the ability to detect GERD compared with pH-metry alone in patients with GERD-related symptoms, either typical or atypical. MII-pH is able to provide more information and to exclude GERD diagnosis definitively in PPI non-responder patients such as those with functional heartburn.

\section{REFERENCES}

1. Bortoli N, Martinucci I, Bertani L, Russo S, Franchi R, Furnari M, Tolone S, Bodini G, Bolognesi V, Bellini M, Savarino V, Marchi S, Savarino EV. Esophageal testing: What we have so far. World J Gastrointest Pathophysiol. 2016;7:72-85.

2. Dehghani SM, Taghavi SA, Javaherizadeh H, Nasri M. Combined 24-hours esophageal $\mathrm{pH}$ monitoring and multichannel intraluminal impedance for comparison of gastroesophageal reflux in children with typical versus atypical symptoms of gastroesophageal reflux disease. Arq Gastroenterol. atypical symp

3. Frazzoni M, Manta R, Mirante VG, Conigliaro R, Frazzoni L, Melotti $\mathrm{G}$. Esophageal chemical clearance is impaired in gastroesophageal reflux disease - a 24-h impedance- $\mathrm{pH}$ monitoring assessment. Neurogastroenterol Motil. 2013;25:399-406.

4. Kessing BF, Bredenoord AJ, Weijenborg PW, Hemmink GJ, Loots CM, Smout AJ. Esophageal acid exposure decreases intraluminal baseline impedance levels. Am J Gastroenterol. 2011;106:2093-97.
5. Mainie I, Tutuian R, Shay S, Vela M, Zhang X, Sifrim D, Castell DO. Acid and non-acid reflux in patients with persistent symptoms despite acid suppressive therapy: a multicentre study using combined ambulatory impedance-pH monitoring. Gut. 2006;55:1398-402.

6. Martinucci I, de Bortoli N, Savarino E, Piaggi P, Bellini M, Antonelli A, Savarino V, Frazzoni M, Marchi S. Esophageal baseline impedance levels in patients with pathophysiological characteristics of functional heartburn. in patients with pathophysiological charact

7. Moraes-Filho JP, Chinzon D, Eisig JN. Prevalence of heartburn and gastroesophageal reflux disease in the urban Brazilian population. Arq Gastroenterol. $2005 ; 42: 122-7$.

8. Tsoukali E. Sifrim D. Investigation of gastroesophageal reflux disease. Ann Gastroenterol. 2013;26:290-5.

9. Vakil N, van Zanten SV, Kahrilas P, Dent J, Jones R. The Montreal definition and classification of gastroesophageal reflux disease: a global evidence-based consensus. Am J Gastroenterol. 2006;101:1900-20. 


\section{Erratum}

In Editorial "Multichannel intraluminal impedance and $\mathrm{pH}$ " published in journal Arquivos de Gastroenterologia, v.53(3):129, which was read: I read with interest the article by Bortoli $\mathrm{N}$ et al.(2)

read:

I read with interest the article by Dehghani SM et al.(2)

In the references list which was read:

2. Dehghani SM, Taghavi SA, Javaherizadeh H, Nasri M. Combined 24-hours esophageal pH monitoring and multichannel intraluminal impedance for comparison of gastroesophageal reflux in children with typical versus atypical symptoms of gastroesophageal reflux disease. Arq Gastroenterol. 2016;53:XXX

read:

2. Dehghani SM, Taghavi SA, Javaherizadeh H, Nasri M. Combined 24-hours esophageal pH monitoring and multichannel intraluminal impedance for comparison of gastroesophageal reflux in children with typical versus atypical symptoms of gastroesophageal reflux disease. Arq Gastroenterol. 2016;53:130-5. 